\title{
Pharmacy Practice in Malaysia
}

\author{
Wong Sie Sing
}

8 Jalan Court House, 93000 Kuching, Sarawak, Malaysia

\begin{abstract}
Pharmacists in Malaysia practise their profession in rugged terrains which demand both professional skills and pioneering spirits. Many of the current pharmaceutical standards, practices, and legislations need overhauling in order to meet the aspiration of the nation in this new millennium. The Malaysian Pharmaceutical Society has a vital role to play. The profession requires the greatest understanding of the Malaysian Medical Association and the Government in this transition period.
\end{abstract}

Keywords: pharmacy practice, pharmacy standards, legislations, healthcare, Malaysia

\section{INTRODUCTION}

Pharmacy is a learned profession. It is a wellestablished science-based profession which possesses all the essential characteristics of a professional group. Four main characteristics reflect the profession's distinctiveness: the special sphere of knowledge and intellectual discipline, well defined functions, professional ethics and conduct, and practitioners representative body. Persons who desire to partake in the profession need to master the pharmaceutical sciences.

The first distinctive characteristic concerns the special sphere of knowledge and intellectual discipline. Knowledge in the pharmaceutical sciences may be acquired through undergraduate pharmacy degree courses presently available locally in Universiti Sains Malaysia, Universiti Malaya, Universiti Kebangsaan Malaysia, International Medical University, Sepang Institute of Technology and Sedaya College. In addition to these six institutions of higher education, Universiti Teknologi Mara and International Islamic University are expected to offer pharmacy degree course soon. Pharmacy graduates from 56 other overseas universities, in 13 countries, are also recognized by the Pharmacy Board (1). Only pharmacy students who have satisfactorily completed the prescribed course are permitted to embark upon the compulsory twelve months of pre-registration training in an establishment recognized by the Pharmacy Board. Currently a pre-registration pharmacy graduate has a choice to receive training in either hospital pharmacy, community pharmacy, manufacturing pharmacy or wholesale trading pharmacy.

The second feature is the presence of a national body representing all the pharmacy practitioners. Malaysian Pharmaceutical Society (MPS) was formed and incorporated under the Society Act in 1965. It promotes pharmaceutical practice, protects the interests of the practitioners and end-users, and encourages the advancement of the pharmaceutical sciences. It is interesting to add here that another two pharmaceutical societies, namely Sabah Pharmaceutical Society and Sarawak Pharmaceutical Society also co-exist to champion the pharmacy profession in the states of Sabah and Sarawak, respectively.

The third feature relates to the professional ethics and conduct which guide all members. The Council of MPS had issued a guideline on the matter. Uniquely the Pharmacy Board had also issued the "Code of Conduct For Pharmacists and Body Corporates". By virtue of the power given to 
the Pharmacy Board under Section 22(1)(e) and (j) of the Registration of Pharmacists Act 1951, this document may be legally binding upon the pharmacists.

The fourth feature of a learned profession is the provision by its practitioners of uniform professional services and advice to the public. This refers to the supply of medicines to the public, accompanied by appropriate advice (that is, patient medication counseling) during the dispensing process.

Pharmacy, as a learned profession, was rarely challenged since time immemorial. The inherent dynamism has brought it through several rounds of professional metamorphosis. As a result, the practice of pharmacy has been described in a variety of ways.

\section{WHAT IS PHARMACY PRACTICE?}

Differing views have been presented on this matter. Some consider it a profession, others look at it as a trade - albeit a professional one. There is no concise and precise description on what pharmacy practice should be. Perhaps the difficulty is due to the co-existence of both specialized and generalized professional services which the profession offers.

Nonetheless, pharmacy practitioners all agree that pharmacists ought to know the properties (which include pharmacodynamics, pharmacokinetics, mechanisms of drug action, side-effects, adverse drug-drug reactions, adverse drug-food reactions, and drug toxicity) of all the medicines, their formulation processes, proper storage conditions, and appropriate usage. Such knowledge should be applied primarily towards public interests during the course of our profession activities. These professional activities pertain to the supply of medicines for humans, supply of veterinary medicines, infant and enriched formulas for adults, sick-room appliances, agricultural, horticultural and industrial chemicals, scientific apparatus (such as stethoscopes and clinical thermometers), surgical appliances and instruments, electromedical therapeutic apparatus (such as blood pressure meters and blood glucose or cholesterol monitors). But many pharmacies also offer nonprofessional activities which are often closely associated with pharmacy, such as the supply of perfumes, cosmetics, toilet requisites and photographic materials.
Pharmacy practice in Malaysia varies from one pharmacy to another. Chain-store pharmacies usually offer a significant proportion of nonprofessional services and activities alongside the traditional professional services. Smaller independent pharmacies normally focus on professional pharmacy services. Both types are representative of private pharmacy practice in Malaysia. On the other hand, pharmacy practice in the government sector is quite different. Government pharmacists enjoy a more favourable legal environment which permits them complete control over the supply of medicines. Government doctors do not provide pharmacy services to patients, unlike their counterparts in private practice. Consequently, private pharmacies operate under very harsh and unfavourable conditions imposed by legal and historical limits. Many community pharmacies do not even receive one prescription chit a day! This unhealthy scenario should be rectified by the government, with the full understanding of the Malaysian medical profession. It is hoped that the pharmacy profession will be granted a new lease of life in this new millennium.

\section{PHARMACY PRACTICE IN THE NEW MILLENNIUM}

Malaysia is one of the front-runners amonst developing countries in this high technology information era through the creation and implementation of the world renowned Multimedia Super Corridor. Our nation ranks $16^{\text {th }}$ as a world trading nation, and we are a signatory to almost all international treaties including global trade liberalization related to the World Trade Organization. Global trade liberation will inevitably be accompanied by a free flow of professionals (such as lawyers, accountants, pharmacists and doctors). With a relatively lower pharmacist to population ratio coupled with a comparatively higher salary in our country, neighbouring foreign pharmacists will flow into Malaysia to fill up any shortage. We may not be prepared sufficiently to handle the situation to the national advantage. The interests of local practitioners may be damaged. In this context, the pharmacy profession in Malaysia needs to work doubly hard so as not to be caught unprepared.

Against such a background, MPS has risen to the occasion by examining the various professional issues and putting in place necessary strategies to enhance professionalism in every aspect of the 
pharmacy practice. The undersigned feels strongly that Malaysian pharmacists need to address the following matters in order to be able to contribute more meaningfully, as an important primary healthcare team member, to the overall health of the nation:

\section{(a) Control over the supply of medicines}

As mentioned earlier, private medical doctors control a large percentage of medicines supplied to patients. It is high time that this control be exclusively given to pharmacists who, after all, are the only professionals properly trained for the job. In 1984, the Malaysian Medical Association (MMA) had agreed, in principle, that the present system should change for the better. Physicians should focus on diagnosis and prescribing. The dispensing of medicines had been mutually agreed to be the professional role of pharmacists and should, therefore, be implemented for both the public, as well as the private sector.

Many brainstorming sessions have been held on this matter. Finally, MPS launched in 1998 Project 2003 to spearhead this professional activity. Seven sub-committees (namely Pharmacy Practice Standards Committee, Professional Competence Committee, Professional Image and Public Education Committee, Telepharmacy Committee, Pharmacy Legislation Committee, Manpower Projection Committee, and National Drug Policy and National Healthcare System Committee) were established to examine and prepare reports on various important aspects of the profession. It is hoped that a formal official recommendation will be ready for submission to the Government by the middle of 2001.

\section{(b) National Healthcare Fund}

National healthcare bills have risen sharply in recent years. Health expenses in 1999 were reported at about four and a half billion ringgit. There is a need to cap and control the bill and to involve citizens in this important matter. As a caring and well-planned nation, it seems an excellent idea to introduce a National Healthcare Fund to finance all future needs of the people in our medication-treatment. It should be by and for the people. The government also needs to budget for it because about one-third of the population will require subsidy.

Indeed, Malaysia cannot afford not to plan ahead for a National Healthcare Fund or a similar scheme because in about 10 years' time, a fifth of our population would have aged beyond 65 years. The geriatric population requires a bigger budget for health matters. And it will not get cheaper as the years go by.

The National Healthcare Fund should finance all medicines supplied. Pharmacists should be paid a professional fee for services rendered to the public. This will enhance the professional image of pharmacists, and place us at par with other professionals in Malaysia. MPS needs to contribute proactively, through seminars and public talks, singularly as well as collectively, with other stakeholders (namely MMA, allied health bodies, consumer groups, Insurance and Managed Care Organizations) to work out a win-win formula for all the health service providers and users.

\section{(c) Even distribution of pharmacy services}

The present 3000-plus registered pharmacists is expected to increase to about 5000 by the year 2004. MPS needs to ensure an even distribution of pharmacies throughout the country. Some sort of pharmacy zoning system may be necessary. The populace should be entitled to receive similar standards of pharmacy services to that in the big cities. A duty roster will ensure round-the clock availability of medicines to needy patients.

In cities such as Kuala Lumpur, Kota Kinabalu, Kuching, Johore Bahru and Penang, there are probably too many private community pharmacies catering to the needs of city dwellers. Perhaps newcomers should be given incentives or legislated to set up pharmacies in small towns and rural areas. In rural places where there are no private clinics, private community pharmacies can still complement the services provided by the government's rural clinics. A town of 30,000 people requires about three private community pharmacies to work side by side with the public/hospital pharmacies. Distribution of pharmacies should be worked out on a district basis.

It was reported that there are about 350 pharmacists working in government hospitals, clinics, laboratories and stores (MMA press release, $24^{\text {th }}$ August 2000). This represents about $13 \%$ of all practising pharmacists. However, $45 \%$ of the medical practitioners work in the public sector. Obviously the national pharmacist shortage lies in the public sector. Urgent action needs to be 
taken by the government to rectify this problem.

The Health Minister announced, on $9^{\text {th }}$ December 2000 , the requirement for a compulsory three-year government service for all newly qualified dentists, effective from $1^{\text {st }}$ January 2001. It is time that pharmacists join the doctors and dentists in compulsory national government service. This is in line with the present global paradigm shift in healthcare delivery.

\section{(d) Self-regulation in pharmacy standards and practice}

There is a need for a paradigm shift in allowing the learned profession to be self-regulated in matters pertaining to pharmacy standards and practice. These refer to ethics and conduct of pharmacists, the continuing competence of members to practise, and assessment of new entrants into the profession.

Some other professional groups in Malaysia (such as the MMA and Malaysian Advocates Society) have been self-regulating in these matters. It is a step forward which will inevitably bring much benefit to the people.

Continuing Pharmacy Education (CPE) for the practising pharmacists is a universal trend carried out by most advanced nations. The United States of America and the United Kingdom adopt different CPE systems. Perhaps the MPS-CPE pioneering project can form the basic framework to build upon. Seminars, conferences and certain write-ups can be a basis for assessment. To capture all CPE efforts, it may be reasonable and feasible to adopt the American Log-Book system where the onus to maintain records lies with the practitioners. The Royal Pharmaceutical Society of Great Britain (RPSGB) had introduced the Continuing Education Logbook in 1995 (2). The RPSGB are in the process of consulting its 40,000 members in working out a new framework for professional regulation with measures to ensure professional competence and lifelong learning (3).

Our present pre-registration training programme has its form but lacks mechanisms for monitoring the actual progress of students. Visual assessment may not be sufficient and objective enough. Regular intervals of written assessments are preferable. The pharmacist-supervisors' input will depend on his/her experience and knowledge. A systematic write-up on what to impart and a standard list of reference books/materials should standardize the supervision. Wholesale trading pharmacy and manufacturing pharmacy do not expose the pre-registration students to adequate patient counseling. Many students are left to 'learn on their own'. It is vital for the profession to acertain whether it is important for all students to attain the same breath and depth of professionalism in the different disciplines.

The undersigned recommends the New Zealand system that was recently implemented. Since 1997, all newly qualified pharmacy graduates in New Zealand undergo a twelve-month pharmacy preregistration training program which defines seven professional competency standards expected of a registered pharmacist. A combination of on-the-job assessment, submission of assignments, performance at training days, completion of a learning record, and attendance at a final assessment centre determines the standards achieved (4). Australia is likely to follow a similar competence-based accreditation for pharmacists (5).

\section{(e) Education and research}

Pharmacy has been designated as one of the priority development areas in our knowledge based new economy which our government is very determined to nurture. Pharmacy educationists need to ensure that our profession is well positioned to derive optimal growth. The choice of subjects in undergraduate pharmacy degree programmes ought to provide wide coverage and sufficient depth in all the pharmaceutical sciences. Postgraduate studies should produce specialists in various disciplines such as pharmaceutics, pharmacognosy, synthetic-medicinal chemistry, clinical pharmacy and pharmaceutical biotechnology. Our educational system needs to produce both generalists as well as specialists who will contribute to the further advancement of the profession.

The local pharmaceutical industry may form a symbiotic partnership with academicians. The latter can generate the much needed input in basic pharmaceutical science research. The former can commercialize useful products or applications for mutual benefit. This modulus of operation is a norm in many advanced countries.

A sound pharmacy education system with emphasis and smart partnership in research and development will surely bring forth tremendous progress to the pharmacy profession in Malaysia. Greater and closer co-operation between 
pharmaceutical scientists in universities and the pharmaceutical industry in areas such as production of raw material for pharmaceuticals, synthesis of new and useful chemical entities, biotechnology in manufacturing, design of new and better methods in extraction of active ingredients from local medicinal plants, formulation, and general transfer of technology from the academic scientists to the pharmaceutical industry should be encouraged.

\section{(f) National Formulary and Pharmacopoeia:}

A hallmark of a learned profession is a systematic accumulation and compilation of new knowledge into reference standards or specifications which posterity can build upon for greater advancement. The legal profession has unmatched achievement in this matter. All advanced western nations have built up their own wealth of knowledge and technology over a long period of time. After being independent for four and a half decades, Malaysia should begin to build its own Pharmacopoeia and National Formulary.

It is a matter of grave concern that many locally concocted medicinal preparations are not properly documented. Many rural folks ("village doctors") have been using selected plants as medicines for generations. This knowledge of traditional medicine needs to be preserved in writing (into Formulary or Pharmacopoeia) before these old folks leave us for good.

Even worse still is the fact that we may lose a large range of indigenous plants during our rapid economic development. Malaysia is blessed with about 12,500 species of medicinal plants (6) which can be a valuable source of new drugs. As much as $50 \%$ of modern medicines have been derived from plants, the majority of them from the tropical forest (7). The Malaysian forest represents one of the richest of the region's tropical forest but is also in serious danger of over-exploitation.

Much research has been initiated by local scientists in the fields of natural product chemistry but the scientific impact these efforts has generated is minimal. Much of the activities are confined to detecting and identifying the chemical constituents that possess biological activity and are often discontinued at the juncture where critical animal or human testing is required further (8).

The Malaysian Herbal Products Blueprint was launched in September 2000 by the Malaysian
Industry-Government Group for High Technology (MIGHT). It is hoped that MIGHT will give equal emphasis to research and development and produce monographs on Malaysian herbs, in addition to developing and promoting the local herbal industry (9).

Perhaps it is the right time for all the six local institutions of higher learning where pharmacy is taught to jointly initiate and spearhead a national project in establishing an Institute of Pharmaceutical Research, parallel to the Institute of Medical Research.

It is also high time for MPS to work side by side with MMA in recommending to the government of a permanent committee, comprising of experts from various medical and pharmaceutical specialities, to bring into being a National Pharmacopoeia and Formulary.

\section{(g) Pharmacy legislation:}

The Poisons Act 1952 (Revised 1989) and Registration of Pharmacists Act 1951 (Revised 1989) are the two main pillars of pharmacy law in Malaysia. Other pieces of legislation such as the Dangerous Drugs Act 1952 (Revised 1980), Sale of Drugs Act 1952 (Revised 1989), and Medicines (Advertisement and Sale) Act 1956 (Revised 1983) are built upon these two laws. It is quite apparent that these acts were first formulated with strong British Colonial characteristics. Although these laws have been reviewed during the last decade, much of the reviews were piecemeal in nature without much forward vision and strategy in developing the pharmacy profession. With the advent of the Information Technology Era, our present pharmacy legislations are obviously not equipped to deal with matters such as electronic prescribing, digital signature, Telemedicine and Telepharmacy. Significant overhauls are the order of the day.

It is imperative that Telepharmacy and Internet pharmacy should also comply completely with all pharmacy legislations. Professional ethics and high standards should be maintained. Medicines should only be delivered to patients in person. Systems and mechanisms to detect and to verify the prescriber's signature that come with electronic prescribing should be in place. Malaysian cyberspace legislations for pharmacy practice need to be incorporated.

A paradigm shift and legislation overhaul are 
suggested for the following areas of pharmacy practice:

(i) exclusive control over the supply of medicines by the pharmacists;

(ii) re-classification Group D Poisons as Group C Poisons;

(iii) pharmacists' control over the supply of herbal and traditional medicines/products;

(iv) introduction of an annual practising certificate to replace the present annual retention certificate and Type A Licence;

(v) self-regulation in professional matters such as ethics and conduct, practice standards, and continuing education;

(vi) introduction of a compulsory three-year national service for all new pharmacists; and

(vii) introduction of pharmacy cyberspace legislation to deal with Telepharmacy and Internet-Pharmacy.

\section{CONCLUSION}

Pharmacists in Malaysia practise under two different sets of legal-historical framework. Government employed pharmacists enjoy complete control over the supply of medicines. They are even exempted from many pharmacy regulation provisions. On the other hand, private pharmacists do not have full control over the supply of medicines. Medical doctors, in the private clinics and private hospitals, still dispense medicines to their own patients. This doctordispensing practice has been allowed since the Colonial era when Malaysia suffered from acute shortage of all professionals. This outdated and unhealthy situation must change in the near future. The government needs to legislate such a change. As a developing country, Malaysia has already been served with a reasonable ratio of pharmacists to doctors per given population. The national ratio of private pharmacists to private doctors is 1 to 2.4. There are 5400 private practising doctors and 2300 private practising pharmacists. We have already achieved the optimal ratio of one doctor to three pharmacists in the urban places. With the annual increase of about 450 new pharmacists from now on, there is a serious threat of unemployment for the pharmacists in a few years' time.

On the other hand, there are insufficient numbers of pharmacists working in the public sector. Urgent measures must be worked out to rectify the situation. The acute shortage of pharmacists in the public sector may be overcome with the new entrants. The government's 118 hospitals, 772 health clinics and 1992 rural clinics (Statistics Dept. Bulletin-1999) certainly need to employ many more pharmacists in order to render quality services to the people.

MPS needs to work hand-in-hand with the Government Planning Unit to map out a thorough manpower projection for pharmacists and the supporting staff over the next decade.

The pharmacy profession needs the greatest understanding of the medical profession and the consumer groups in working out the most appropriate healthcare delivery system in the interests of the people in this country. MPS has a vital role in leading pharmacists through this transition period into a new type of pharmacy practice. This new kind of pharmacy profession envisaged will be more fitting for a fast developing country like Malaysia. Vision 2020 will certainly be incomplete if pharmacists fail to rise to the occasion in building a professional and caring pharmacy practice for the nation.

\section{$* * * * *$}

\section{REFERENCES}

1. Kelayakan Farmasi Dari Institusi Pengajian Tinggi. Malaysian Pharmaceutical Society. http://www.mps.org.my/html/universiti_yang_ diiktiraf.htm (5 Apr. 2001).

2. Continuing education logbook for 1999. Pharm J 1999;262:15.

3. Society starts consultation on a new framework for professional regulation. Pharm J 2000;
264: 4000.

4. Shaw JP, Drumm D. Prescription for registration: The New Zealand pharmacy pre-registration training programme. Pharm J.1999;263:98-101.

5. Caldwell J. NZ Society introduces practice certificate based on competence. Pharm J 2000;265:320.

6. Latiff A. Traditional use, potential for 
exploitation and conservation of medicinal plants in Malaysia. In: Proceedings of the Seminar on Traditional Herbs and Medicinal Plants in Sarawak; 2000 Oct. 10; Kuching : Sarawak Development Institute, 2000.

7. Chai PPK. Global perspectives on the herbs and medicinal plants industry. In: Proceedings of the Seminar on Traditional Herbs and Medicinal
Plants in Sarawak; 2000 Oct 10; Kuching: Sarawak Development Institute, 2000.

8. Ghazally I, Murtedza M, Laily BD. Chemical Prospecting in the Malaysian forest 1st ed. Malaysia: Pelanduk Publications; 1995.

9. Malaysian Industry-Government Group for High Technology. October 2000. http://www.might.org.my (5 Apr. 2001).

From page 14

\section{Continuing Pharmacy Education question:}

Study this case and give your response (100-200 words) based on the bioethical principles outlined in the CPE article on page 9. You may earn 2 CPE points if you submit a credible response to the MPS-CPE Secretariat at the Malaysian Pharmaceutical Society, P.O. Box 158, Jalan Sultan, 46710 Petaling Jaya, Selangor.

As a pharmacist at a regional transplant centre, you are in the team that allocates organs for transplantation. Your committee is at a deadlock as to which option to choose. The first is to allocate according to need (the sickest person gets the organ). The second option is to allocate according to an ordered pair. In the ordered pair formula, people who have abused their bodies (a heavy smoker) will be considered only after others who have not abused their bodies have received their transplants. The third proposal suggests that those who have agreed to be organ donors (usually by a pledger card that they carry) should be put at the top of the list. Your vote is key for the majority. Who will you vote for? Why? 